\title{
Marine sediments as a source of dissolved Nickel to the global ocean
}

\author{
S. BRUGGMANN ${ }^{1}$, S. SEVERMANN ${ }^{1}$, J. MCMANUS $^{2}$
}

${ }^{1}$ Rutgers, The State University of New Jersey, 71 Dudley Rd., New Brunswick, NJ 08901, United States

${ }^{2}$ Bigelow Laboratory for Ocean Sciences, 60 Bigelow Dr., East Boothbay, ME 04544, United States

Nickel (Ni) is a micronutrient that is essential for marine life. The distribution of $\mathrm{Ni}$ in the marine environment reflects its cycling with the biological pump. In addition to organic matter, Ni cycling in seawater is influenced by the cycling of $\mathrm{Fe}$ and $\mathrm{Mn}$ oxides. These carrier phases thus have the potential to serve as either a source or a sink for $\mathrm{Ni}$. Indeed, the oceanic budget of $\mathrm{Ni}$ requires a substantial recycled $\mathrm{Ni}$ component and our data indicate that marine sediment may be an important source of this $\mathrm{Ni}$.

This study presents concentrations of $\mathrm{Ni}$ and other metals in pore fluids and sediments from study sites on the California and Mexican margin. Our results show variable Ni concentrations in pore fluids that range from typical bottom water concentrations $(\sim 15 \mathrm{nM})$ up to $2 \mu \mathrm{M}$. These elevated dissolved concentrations occur at locations of high and low bottom water oxygen concentrations. Diffusive flux calculations suggest that all sites investigated here are a benthic souce of $\mathrm{Ni}$, with fluxes as high as $10 \mathrm{nmol} \mathrm{cm} \mathrm{y}^{-2}$. Where pore fluid Mn concentrations are high $(\approx 50$ to 100 $\mu \mathrm{M} \mathrm{Mn}), \mathrm{Ni}$ concentrations are also high, suggesting metal oxides as a source of $\mathrm{Ni}$ to pore fluids. However, at the more reducing sites where there is little pore fluid $\mathrm{Mn}$ and $\mathrm{Fe}$, but where $\mathrm{C}_{\text {org }}$ burial rates are high, we propose that high pore fluid $\mathrm{Ni}$ derives from a source other than amorphous oxides. Such potential sources are lithogenic mineral phases or organic matter. The resultant high $\mathrm{Ni}$ concentrations in pore fluids indicate that any authigenic phase discriminates against $\mathrm{Ni}$ during their formation and at least during the earliest phases of diagenesis. 